\title{
DROGAS E SOCIEDADE: MATERIAL DE APOIO A ATIVIDADES EDUCATIVAS NA PERSPECTIVA EMANCIPATÓRIA
}

\author{
DRUGS AND SOCIETY: SUPPORTING MATERIAL FOR EDUCATIONAL \\ ACTIVITIES IN THE EMANCIPATORY PERSPECTIVE
}

DROGAS Y SOCIEDAD: MATERIAL PARA APOYAR LAS ACTIVIDADES

DE EDUCACIÓN EN LA PERSPECTIVA EMANCIPADORA

\author{
Iara Ribeiro Paixão ${ }^{1}$ \\ Cassia Baldini Soares ${ }^{2}$ \\ Luiza Carraschi de Oliveira ${ }^{3}$ \\ Luciana Cordeiro ${ }^{4}$ \\ Carla Andrea Trapé \\ Celia Maria Sivalli Campos ${ }^{6}$
}

Resumo O objetivo deste artigo é apresentar o processo de elaboração de material educativo para apoiar ações com jovens, na temática das drogas, resultado de pesquisa-ação emancipatória, desenvolvida ao longo de 14 oficinas, com pesquisadores e trabalhadores da saúde. Foi organizado em três eixos: o da dimensão estrutural, que analisa o fenômeno produção-distribuição-consumo de drogas no contexto da estrutura e da dinâmica social contemporânea; o da dimensão superestrutural, que discute ideologia e valores hegemônicos na sociedade contemporânea e sua relação com o fenômeno das drogas; e o eixo que analisa as respostas da juventude frente às contradições sociais, com discussão sobre a possibilidade de organização política como processo de fortalecimento da juventude para o enfrentamento dos desgastes. As partes que compõem cada eixo são: um texto-base; indicação de filmes e textos complementares; questões para aprofundar a discussão; e estratégias pedagógicas. O material didático favorece processos educativos críticos e radicais, aqueles que expõem as contradições sociais que estão na base do fenômeno produção-circulação-consumo de drogas, e superam formações que tomam como foco a droga e que culpabilizam o usuário, processos que comumente afastam os jovens da discussão.

Palavras-chave usuários de drogas; educação em saúde; jovens; enfermagem; pesquisa-ação.
Abstract The objective of this article is to present the process of elaboration of educational material to support actions with young people in the thematic of drugs, result of emancipatory action research, developed during 14 workshops, with researchers and health workers. It was organized in three axes: the structural dimension, which analyzes the production-distribution-drug-consumption phenomenon in the context of contemporary social structure and dynamics; the superstructural dimension, which discusses hegemonic ideology and values in contemporary society and its relation to the phenomenon of drugs; and the axis that analyzes the responses of youth to social contradictions, with discussion about the possibility of political organization as a process of strengthening youth to cope with distress. The parts that make up each axis are: a base text; indication of films and complementary texts; questions to deepen the discussion; pedagogical strategies. The didactic material favors critical and radical educational processes, those that expose the social contradictions that are at the basis of the production-circulation-drug-consumption phenomenon, and overcome formations that focus on the drug and that blame the user, processes that commonly put away the young people of the discussion. Keywords drug users; health education; youth; nursing; action-research. 


\section{Introdução}

As estatísticas evidenciam os sérios problemas que atingem a juventude brasileira. Os jovens constituem a maior população carcerária no Brasil. Parte significativa dos crimes está relacionada com o tráfico de drogas (Brasil, 2015). As estatísticas também são alarmantes quando se compara a relação de vítimas por arma de fogo entre a população jovem (entre 15 e 29 anos) e não jovem (com 30 anos ou mais). No Brasil, em 2012, morreram 285\% mais jovens do que não jovens (Waiselfiz, 2015), o que é ainda mais alarmante se considerarmos que a faixa etária entre 15 e 29 anos representava $26,9 \%$ do total da população em 2010.

Um dos problemas, o envolvimento de jovens com o tráfico de drogas, é analisado por Boiteux (2015) como a possibilidade de inserção de jovens em atividade que oferece rendimentos, o que permite o aumento considerável do poder de consumo. O tráfico recruta jovens da periferia, geralmente aqueles não inseridos no mercado formal de trabalho.

Ao mesmo tempo em que viabiliza o consumo, envolve os jovens em situações de violência, não apenas nas situações características da atividade do tráfico, mas também nas perpetradas pelo Estado - encarceramento e violência policial, como parte dos resultados perversos da guerra às drogas (Boiteux, 2015; Zaccone, 2012; Arguello e Dieter, 2014).

O começo do século XX instaurou um período histórico de notável intolerância ao uso de drogas, denominado de proibicionismo (Carneiro, 2005), que tem embasado as diversas políticas estatais de cunho social, dentre elas as de saúde, que tomam como finalidade a eliminação do consumo das substâncias classificadas como ilícitas (Alves, 2009). Esta finalidade determina, na área da saúde, programas que visam à prevenção do uso e ao tratamento da dependência, focado na abstinência (Global Commission on Drug Policy, 2011), objetivos mais afeitos à idealização do que a possibilidades reais, e estimula medidas repressivas dirigidas aos que produzem, distribuem ou consomem drogas ilícitas.

Avaliações dessas estratégias têm acumulado críticas e proposto mudanças no enfoque das políticas globais relacionadas ao consumo de drogas (Global Commission on Drug Policy, 2011). Há críticas relacionadas aos projetos educacionais voltados a esta temática (Soares e Jacobi, 2000) e aos encaminhamentos da área saúde (Ribeiro e Minayo, 2015).

Revisões sistemáticas da literatura sinalizaram a falta de efetividade de ações comumente direcionadas a jovens, com o intuito de prevenir o uso de substâncias psicoativas (Gates et al., 2006). No âmbito escolar, são mais eficientes as ações que promovem sociabilidade (Faggiano et al., 2014) e que potencializam as relações entre os estudantes. São mais efetivas do que as pro- 
paladas ações enfocadas no 'diga não' às drogas (Fletcher, Bonell e Hargreaves, 2008). No que diz respeito a campanhas midiáticas sobre drogas, resultados de estudo de Allara et al. (2014) mostraram a necessidade de precaução, uma vez que podem produzir efeitos inesperados, e até mesmo nocivos à população que se quer alcançar.

A pesquisa que originou este artigo foi ancorada em conceitos do campo da saúde coletiva; portanto, considera juventude como categoria social. No modo de produção capitalista, a juventude é a etapa em que a sociedade investe nos jovens com vistas à preparação para o trabalho e para a reprodução da família e dos valores da classe social, para reproduzi-la (Soares, 2009a).

Os valores e as normas sociais, processados pelas agências de socialização (as primeiras são a família e a escola), são apreendidos e incorporados ao longo da vida e servem como balizas para a vida em sociedade (escolha profissional, constituição de família, participação social, dentre outras) (Soares, 2009b). Essas agências de socialização sofrem modificações radicais no capitalismo moderno. Dowbor (2010) sinaliza transformações estruturais da sociedade, como as que trazem o desemprego, que repercutem na capacidade das famílias de garantirem a sobrevivência de seus membros. Quanto à sua configuração e à convivência de seus membros, a tendência é de haver múltiplos arranjos, restrição ao convívio familiar, e à situação de pessoas que apenas dividem a residência, muitas vezes casas-dormitórios. Pereira-Pereira (2010) analisa que, no neoliberalismo, a família é instada a garantir a proteção social, para tentar compensar a diminuição do Estado para as políticas de seguridade social.

A segunda agência de socialização, a escola, tem sido constituída como lugar social “(...) ligado ao processo de formação da força de trabalho e de preparação do indivíduo para as responsabilidades sociais (civis, políticas etc.)", processo esse que é desigual entre jovens de diferentes classes sociais (Viana, 2012).

A atual precarização do trabalho e o crescente desemprego têm determinado aos grupos sociais das frações instáveis da classe trabalhadora dificuldade de inserção do mercado de trabalho, o que é ainda mais acentuado entre os jovens dessa classe. Já entre os jovens das classes sociais em que a família pode arcar com a redistribuição da renda no núcleo familiar, a dificuldade de inserção na vida adulta por meio do emprego formal tem sido enfrentada com a ampliação do tempo de escolarização do jovem e da permanência na residência dos pais. Portanto, viver a juventude está na dependência da inserção de classe social da família do jovem(Viana, 2012).

Para compreender o envolvimento dos sujeitos com o complexo fenômeno da produção-distribuição-consumo de drogas, é, portanto, imprescindível partir da análise das condições de produção e reprodução da existência desses sujeitos na sociedade capitalista contemporânea, que determinam tanto as 
características do envolvimento quanto as dos desfechos a ele relacionados, e que são expressos diversamente “(...) na expressão diferenciada do consumo de drogas entre os jovens, dos prejuízos advindos desse consumo e da maneira como os jovens e suas famílias acessariam recursos para lidar com o problema" (Soares, 2007, p. 43).

É com essa compreensão conceitual, fundamentada no campo da saúde coletiva, que se propõe a utilização da redução de danos, na perspectiva emancipatória (Santos, 2008, p. 191), aquela que objetiva:

(...) a busca de consciência do lugar que os sujeitos ocupam na sociedade; a percepção das contradições do sistema capitalista e ao mesmo tempo a valorização do humano como ente genérico; a percepção dos interesses em jogo e da necessidade de resgatar os valores de solidariedade para transformar as condições de desigualdade social; enfim, a transformação de sujeitos individuais e passivos em sujeitos coletivos, críticos e emancipados.

Essa perspectiva propõe a superação do proibicionismo, que fundamenta ações de controle social das frações mais empobrecidas das classes trabalhado$\operatorname{ras}^{7}$ submetidas ao sistema de exploração capitalista (Santos, 2008), o que não lhes permite se apropriar dos bens que produzem. Compreender as diferenças de classe e de acesso aos bens possibilita a denúncia das raízes dos problemas advindos do envolvimento dos sujeitos com o fenômeno produção-distribuição-consumo de drogas e, consequentemente, favorece o desenvolvimento de práticas coerentes com essa interpretação (Soares e Campos, 2009). Com base na saúde coletiva cunhou-se o termo redução de danos emancipatória (RDE) (Cordeiro, Godoy e Soares, 2014).

Coerentemente a essa perspectiva e ao compreender a educação como forte componente da RDE, adotou-se neste trabalho a educação emancipatória, que se apoia por sua vez em teóricos da área da educação revolucionária e crítica. Dentre eles destaca-se Dermeval Saviani, ${ }^{8}$ protagonista brasileiro da pedagogia 'histórico-crítica', fortemente influenciada por teóricos marxistas (Almeida, Trapé e Soares, 2013).

Saviani (2003) compreende a educação como mediadora da transformação social e propõe o processo educativo de acordo com as etapas: reconhecimento de uma dada prática social na qual o educador e educando estão inseridos, com diferentes conhecimentos; problematização da realidade com vistas a identificar os principais problemas desse contexto; instrumentalização dos sujeitos envolvidos a fim de que possam (re)interpretar a realidade, a partir da disponibilização de todo o conhecimento produzido; catarse - a incorporação do conhecimento; elaboração e desenvolvimento de novas práticas sociais.

No processo de elaboração de material educativo deve-se, portanto, levar em consideração o conhecimento dos envolvidos (Silva, 2012; Nogueira et al. 
2011; Oliveira, 2011; Freitas e Rezende Filho, 2011), investigando-se previamente a compreensão dos educandos sobre o tema a ser abordado, bem como a realidade social dos sujeitos. De outra forma, o material será construído baseado em questões eleitas da perspectiva do educador (Freitas e Rezende Filho, 2011), que podem constituir-se em instrumentos com função meramente informativa (Nogueira et al., 2011).

Materiais de saúde pública impressos no Brasil sobre drogas estão fundamentados no paradigma da guerra às drogas, pois descrevem estratégias baseadas no proibicionismo, veiculam informações apresentadas de forma autoritária e incontestável e apresentam conteúdos que reforçam o estigma ao usuário de drogas, ao responsabilizá-lo por escolhas saudáveis, impondo ações prescritas pela saúde pública. São constatações que sugerem a necessidade de elaboração de material educativo que seja fundamentado no paradigma da RD na perspectiva emancipatória (Cardoso et al., 2013), conforme descrito por Santos (2008) e Cordeiro, Godoy e Soares (2014), para apoiar atividades educativas e extensionistas (Cardoso et al., 2013).

Este artigo tem como objetivo descrever o processo de elaboração de material educativo impresso, para apoiar atividades educativas com jovens, na temática do consumo prejudicial de drogas, na perspectiva da educação emancipatória.

\section{Pesquisa-ação emancipatória}

Trata-se de pesquisa qualitativa, desenvolvida com a metodologia da pesquisa-ação (PA). ${ }^{9}$ A PA é utilizada por diversas áreas do conhecimento e apresenta várias perspectivas desde a positivista e interpretativa até a crítica (Soares, Cordeiro e Campos, 2013).

Este estudo recorreu à metodologia da pesquisa-ação emancipatória (PAE), coerentemente com os marcos conceituais do campo da saúde coletiva, cujas etapas para operacionalizá-la são descritas por Soares, Cordeiro e Campos (2013), que articulam as etapas da PA com a pedagogia histórico-crítica (Saviani, 2003).

A primeira etapa é o encontro entre o pesquisador que medeia o processo e os participantes que estão motivados a participar da pesquisa. Nesse momento, o pesquisador tem uma síntese prévia sobre o fenômeno a ser compreendido e um projeto idealizado dos passos a serem dados no decorrer do processo investigativo, enquanto os demais participantes portam a compreensão do mesmo fenômeno, com base em suas experiências e com conhecimentos que podem não ser os mesmos. A segunda etapa é a problematização do fenômeno em questão, ou seja, a identificação dos principais problemas vivenciados na prática social e que motivaram o processo de investigação e a mobilização para participar. Nele, já se levantam os pressupostos e se delineiam os obje- 
tivos. Já na terceira etapa o pesquisador responsável pela mediação provê as ferramentas necessárias à instrumentalização da análise do fenômeno em tela, de forma a possibilitar a elaboração da prática social emancipatória. Finalmente, a quarta etapa será a de organização das conclusões e a elaboração da interpretação conjunta sobre o fenômeno, ou o problema, que motivou todo o processo (Soares, Cordeiro e Campos, 2013).

A pesquisa que deu origem ao material gráfico foi desenvolvida por componentes de um grupo de pesquisa. Eram 17 componentes - pesquisadores, trabalhadores da área da saúde e estudantes. Desses, nove participaram de todos os encontros (Pl a P9). Os demais participaram com menos frequência, mas tiveram suas falas consideradas nos resultados como participantes ocasionais (PO). As oficinas contaram também com dois participantes convidados (PCl e PC2), para contribuírem com suas expertises nos temas abordados. Uma vez que na PAE todos os envolvidos são considerados pesquisadores, a mediadora de todo o processo foi identificada como PQ.

O processo desenvolveu-se em 14 oficinas, com duração média de 3 horas, com periodicidade de duas vezes por semana. Essas oficinas tiveram cunho emancipatório, ou seja, foram constituídas como "instrumento que proporciona um espaço de reflexão sobre a práxis, em que os sujeitos - agentes e coprodutores do processo educativo - participam com a finalidade de transformar a práxis reiterativa em práxis criativa" (Soares et al., 2009, p. 192).

Os temas das oficinas foram selecionados mediante avaliação dos pesquisadores sobre as necessidades teórico-práticas presentes em cada oficina. A roda de conversa foi a estratégia eleita em todas as oficinas. O objetivo de cada oficina foi discutido em grupo e a seleção de textos subsidiou a discussão.

O material foi construído de maneira gradual, de acordo com o andamento das oficinas, com pequenos grupos encarregados de finalizar os textos de base. Ao final do processo os pesquisadores tiveram possibilidade de rever todo o material editado e fazer sugestões.

A pesquisa foi aprovada pelo Comitê de Ética em Pesquisa da Escola de Enfermagem da Universidade de São Paulo (parecer n. 1291596). Todos os participantes assinaram o termo de consentimento livre e esclarecido.

\section{As oficinas como um espaço de reflexão}

Os pesquisadores envolvidos na elaboração do material educativo eram enfermeiros (5), psicólogos (3), terapeutas ocupacionais (2) e médica (1). Quase todos tinham concluído outros cursos ou programas após a graduação (especializações em saúde coletiva, dependência de drogas, mestrado, doutorado e pós-doutorado). Eram trabalhadores e professores, ambos da área da saúde, em instituições públicas e privadas. 
A primeira oficina foi guiada pela seguinte questão, elaborada pelos participantes: como construir materiais educativos que não se aproximem da lógica hegemonicamente adotada pela saúde pública, pautada no paradigma da guerra às drogas, construídos com objetivo de prevenir o consumo de drogas, e com conteúdo que focaliza os riscos e agravos consequentes do uso prejudicial de drogas? Como ir além da crítica e construir materiais educativos de cunho emancipatório, pautados no paradigma da redução de danos emancipatória, fundamentada no campo da saúde coletiva? Na etapa de problematização delineou-se um encaminhamento inicial dos temas a serem discutidos.

Assim, a segunda e a terceira oficinas objetivaram discutir a estrutura e a dinâmica sociais, ou seja, a organização da sociedade para produzir e se reproduzir, no capitalismo, um modo de produção fundado na necessidade de exploração de uma classe social pela outra.

Uma síntese parcial dessas oficinas encaminhou para a concordância dos participantes de que um dos conteúdos imprescindíveis do material educativo é a afirmação de que o consumo prejudicial de drogas não é a causa dos problemas sociais; ao contrário, ele é consequência de desgastes produzidos pelas formas de trabalhar e de viver atuais, que tem causado ainda mais desigualdade social e desproteção social mediante instauração da lógica neoliberal no interior do Estado, o que o torna diminuto para as políticas sociais.

A síntese e o uso de substâncias para alterar a psicoatividade humana foram descritos nos diferentes períodos históricos, desde antes da era cristã, como resposta a diversas necessidades sociais e se conforma de acordo com os modos de produção em vigor (Soares, 2007).

O modo de produção capitalista submete as dinâmicas e as relações sociais à sua estrutura e, dessa forma, conforma subjetividades, modos de sofrimento característicos e estratégias de encaminhamento clínico (Safatle, 2016).

Em tempos de profunda reconfiguração da organização do trabalho, determinada pela lógica neoliberal, que preconiza desregulamentação, flexibilização dos vínculos trabalhistas e aumento do desemprego estrutural, a depressão tem sido sinalizada como patologia dominante no mundo (Safatle, 2016).

(...) se anteriormente o sentimento de alienação no trabalho estava vinculado à perda da autenticidade na esfera da ação (...), atualmente nos deparamos com a crença de que cabe apenas ao indivíduo a responsabilidade pelo fracasso na tentativa de autoafirmação de sua individualidade no interior do trabalho. Pois o próprio discurso social é constituído a partir da incitação à autoexpressão de si, ao empreendedorismo de si. (...) (Safatle, 2016, p. 189).

No mesmo sentido, Birman (2009, p. 208) atribuiu as origens da atual cultura juvenil da tatuagem, da violência e do consumo de drogas à insegu- 
rança e à fragilização dessa geração. Essa manifestação, afirma o autor, é resposta ao "desamparo que caracteriza atualmente a juventude, que inscreve e marca dolorosamente no corpo, lancetado pelas tatuagens, a sua condição psíquica torturada".

Assim, na atualidade, a síntese e o uso de drogas (lícitas e ilícitas), tanto as receitadas pelos médicos quanto as vendidas pelos traficantes ou compradas livremente, respondem a diversas necessidades sociais, desde a de regulação do mal-estar dos indivíduos (Birman, 2006) até a de reprodução do capital, como uma commoditie (Soares e Campos, 2009).

Você procura se alienar, dói muito se sentir desprotegido (...), essa sensação de mal-estar é concreta, não é só uma sensação. No dia seguinte talvez o salário não venha (...). Essas coisas estão produzindo um mal-estar e isso combina com a droga, assim como os psicotrópicos (...). A gente não aguenta essa solidão e isso combina com a droga, você toma duas taças de vinho e já fica bem (PCl).

A discussão estimulou os pesquisadores a trazerem as suas vivências e experiências pessoais sobre a temática. Esse processo é muito importante para elaborar um conteúdo que retrate a realidade das oficinas. Esta estratégia permite horizontalizar possíveis hierarquias entre os integrantes do grupo, no que diz respeito à percepção do fenômeno analisado no processo da pesquisa-ação.

Eu só me implico [na discussão] quando existe uma preocupação real ou concreta, o resto é abstração, [aqui] estamos falando com pessoas concretas (PC1).

A quarta e a quinta oficinas tomaram como objetivo discutir as condições de preparo da juventude brasileira para inserir-se no mercado de trabalho (o âmbito da educação) e a inserção propriamente dita (âmbito do trabalho).

Inicialmente o grupo ponderou que o desemprego, que é estrutural no modo de produção capitalista, e a precarização nas relações contratuais de trabalho têm afetado significativamente os jovens, mesmo os que tiveram acesso à formação escolar especializada. Dentre os jovens que precisaram precocemente realizar alguma atividade remunerada para contribuir com o orçamento doméstico, a situação é ainda pior, pois além de terem desgastes advindos da execução de atividades de trabalho precarizado, geralmente se inserem em escolas que não o preparam para a concorrência no mercado de trabalho; isso quando não se desanimam com a falta de perspectivas com a conclusão do curso e interrompem os estudos.

Com base em uma primeira síntese parcial, o grupo buscou aprofundamento teórico para compreender a precarização dos vínculos de trabalho e o próprio desemprego. Para instrumentalizar a discussão, foi debatido o texto de Viana (2012), do qual destaca-se o parágrafo abaixo. 
Essa nova fase [do capitalismo], que expressa um novo regime de acumulação, altera as relações de trabalho no sentido de garantir um processo de aumento da exploração visando combater a tendência declinante da taxa de lucro médio. Nesse contexto, o toyotismo se torna a forma dominante de organização do trabalho no processo produtivo e reorganiza um conjunto de elementos nas relações de trabalho que apontam para uma precarização crescente, e, ao mesmo tempo, produz um desemprego e subemprego em alta escala. Por outro lado, a educação formal também sofre diversas modificações neste contexto, não somente devido ao seu vínculo com as mudanças no processo de trabalho, mas também devido à própria lógica de políticas neoliberais (Viana, 2012, p.175).

Discutiu-se a precarização da educação formal, possível de ser evidenciada desde o ensino fundamental até o ensino superior. Atribui-se peso à mercantilização do ensino e à precarização das condições de trabalho do professor, que desestimulam o educador na construção de práticas educativas emancipatórias.

Levantou-se a necessidade de elaborar, no material educativo, conteúdos que favoreçam a reflexão e compreensão do educador a respeito do objeto a ser transformado no processo educativo.

Como a gente ajuda o professor quando ele encontra uma realidade dessa e fica frustrado? É o que acontece muito nos CAPS (Centro de Atenção Psicossocial). Aí, o cara está com fome, fedido, como eu vou aplicar a minha psicanálise aqui, por que eu entendo que o meu objeto de trabalho não é o ser humano do jeito que ele está, mas a psique humana ou o consumo de drogas? E na educação a mesma coisa, eu não consigo ensinar porque esse cara não tem português, então eu pensei que em algum momento do material, pudesse pensar qual a função dele como educador quando ele encontra um cenário desse; é lamentar ou isso faz parte do que ele precisa transformar como educador?, isso deixa de ser um obstáculo e [se] torna um objeto de trabalho (...). Então, talvez uma parte do material seja para o cara entender que isso faz parte do trabalho dele e não obstáculo, senão a gente corre o risco de ele achar que o material é só para aqueles que podem acessar, os que escrevem, que refletem. Por isso que a escola fica tão chata. (P4)

As estratégias educativas serão eleitas a depender da compreensão do que se quer transformar, ou como geralmente são utilizadas, como reprodução daquilo que se tem domínio. Comumente lança-se mão das aulas expositivas, preleções, nas quais os estudantes são tratados como ouvintes passivos. Ao considerarmos estudantes trabalhadores, de escolas públicas, em cursos noturnos, até mesmo a condição de ouvinte fica prejudicada pelo sono e pelo cansaço.

A educação formal nas escolas tem sido desenvolvida historicamente por meio de disciplinas fragmentadas e centradas na transmissão do conteúdo 
de programas previamente estabelecidos. Os professores em geral tendem a tomar o jovem como um sujeito instável, com inconstâncias de humor e de comportamento, causadas pelas alterações hormonais, e naturalizam a condição juvenil de sujeitos das diferentes classes sociais.

(...) então, a forma [da estratégia educativa] vem em função de uma percepção completamente equivocada desse ser que está na sua frente, ninguém fala em um tom humano igual, dialógico, como dizia Freire. O princípio da dialogia é entender o outro como humano igual, não que sabe menos ou sabe mais (...), não se tem essa dialogia. Os conteúdos teóricos que amparam o trabalho estão completamente equivocados, como é que a gente muda isso? ( $\mathrm{PCl})$

Problematizou-se quais conteúdos do material pedagógico poderiam ajudar o educador a compreender o objeto a ser transformado no processo educativo.

A sexta oficina teve como objetivo discutir a droga, contextualizando-a na complexidade do envolvimento dos sujeitos com o fenômeno produçãodistribuição-consumo. Os componentes da oficina concluíram que a droga na contemporaneidade, seja lícita ou ilícita, tornou-se mercadoria e que é impossível evitar o encontro dos sujeitos com ela; ou seja, é impossível prevenir o seu consumo. A aquisição de mercadorias tem se tornado o sentido do trabalho e o ideal de felicidade está associado ao consumo de mercadorias, de bens materiais ou imateriais.

(...) nós temos pouco tempo para nós mesmos, (...) a impressão que eu tenho é que cada um está muito preso aos seus projetos pessoais. Então o projeto pessoal é o que realiza. Entender esse mecanismo de alienação, quando a gente vai perdendo um pouco o fio da meada do que nós somos enquanto sujeitos que estão no mundo e que valorizam determinadas coisas, que trabalham, que transformam. A gente vai caindo em um lugar que a realização está fora da gente, é essa a questão para o sistema da aparência, a realização sempre está fora da gente, não está conosco, nas nossas relações, na subjetividade que a gente vai construindo (PC2).

No CAPS a gente percebe uma construção de uma sociabilidade que muitas vezes preenche e dá sentindo a muitas coisas. Quando a gente vai fazendo uma redução de danos com essa vertente político-crítica, trabalhando essa questão das relações e os modelos de autossuficiência. Acho que esse conteúdo da discussão é um caminho de disparar outras coisas na relação, o próprio profissional vai descobrindo isso com o tempo, a pessoa que está sendo cuidada vai estabelecendo uma relação diferente (PC2). 
Foi então problematizado pelo grupo como seria um processo educativo emancipatório, que superasse a concepção de jovem como um sujeito frágil e das drogas como substância dominadora.

(...) a pessoa está há 30 anos sem usar e refere que é um dependente químico, não tem química que dure tanto tempo, tem muito mais relação com o modelo mental do que a substância em si, como as pessoas fazem uso disso para não ver outras coisas. Que infelicidade é essa? Que mal-estar é esse? É isso que a gente precisa entender e que atinge as pessoas em cheio, e cada um vai tentar se virar de um jeito (PC2).

Tem grupo que não vai chegar em casa e usar cocaína ou maconha, mas vai chegar em casa e tomar uma dose de uísque (P2).

Por que não problematizar com os jovens os valores que estão em jogo? Essa questão de adquirir um celular roubado é a necessidade de ter um celular, não importa se foi roubado. Isso também acontece com a droga lícita e ilícita. Alguém está preocupado se a droga é licita ou ilícita? (PC2).

O consumo problemático de drogas não é apenas individual, ou seja, as pessoas não usam drogas por serem frágeis ou fracas. O consumo de substâncias está relacionado com o funcionamento da sociedade. A partir dessa compreensão, podemos nos encaixar em movimento sociais que busquem ações de níveis local. Por exemplo: verificar quais são os espaços destinados para a juventude no bairro, verificar recursos públicos existentes para poder compreender como se interfere na vida das pessoas (P2).

Ao término da oficina, concluiu-se que o consumo de drogas, lícitas e ilícitas, está fortemente conectado a necessidades sociais provenientes das relações sociais capitalistas. Assim como acontece com as demais mercadorias, o estímulo ao consumo é engendrado pelo sistema de produção e circulação. A droga é uma mercadoria que, ao mesmo tempo, alivia sofrimentos provenientes de desgastes da vida para uns, e produz lucro para outros. Trata-se, portanto, de uma mercadoria que serve muito bem às necessidades do modo de produção capitalista. Por isso, a síntese do grupo foi na direção de elaborar conteúdo do material educativo de superação da perspectiva idealizada de que é possível prevenir o encontro dos sujeitos com as drogas. Concluiu-se que os conteúdos devem focar no aprimoramento da possibilidade de análise das raízes do fenômeno produção-distribuição-consumo de drogas na sociedade atual. 
Na sétima oficina o objetivo foi sintetizar o processo desenvolvido nas oficinas anteriores, o que resultou na constatação da necessidade de inserir no material educativo conteúdo que contribuísse com a reflexão e identificação pelos educandos de que o ideal de felicidade tem sido vinculado ao consumo de produtos que prometem o prolongamento da juventude, o corpo perfeito, a condição melhor para competir no mercado de trabalho e cujo consumo visa atingir padrões estabelecidos no plano ideal.

A superação poderia ser a construção de respostas coletivas, voltadas ao aprimoramento das condições dos grupos sociais.

E isso tem a ver com valores. Para ocupar determinados espaços devem estar bem vestidos. Quem tem valor? E por que não tem? O modo de produção capitalista vende uma ideia de que o mercado se importa com você, mas se você tiver mérito; tem que merecer, e isto também é um valor. (...) A gente vai caindo em um lugar [em] que a realização está fora da gente, essa é a questão do sistema de aparência. Precisamos ressignificar a questão do consumo e da educação. Então são questões relacionadas aos valores nessa juventude. Daí a gente pensou que os jovens denunciam a crise de valores (...) e isso tem a ver com o sofrimento contemporâneo e o uso problemático de droga. (P4)

A síntese da oficina anterior produziu a necessidade da discussão do conceito de valor, tema da oitava oficina. Os participantes do grupo trouxeram a compreensão acerca dos valores que mobilizam a atividade humana e influenciam tomadas de decisões, de que os valores são desenvolvidos coerentemente com interesses da classe social, e de que há conflitos entre os valores ligados ao bem-estar humano (igualdade, solidariedade, liberdade) e os valores relacionados à reprodução do capital (consumo, individualismo etc.).

Para compreender o conceito de valor e aprofundar a discussão a respeito desses conflitos de valores na sociedade, o grupo leu o texto de Viana (2007), que esclarece a contradição entre os valores autênticos e os inautênticos.

(...) os valores autênticos manifestam a essência humana, ou seja, correspondem a ela. Valores como os de liberdade, igualdade, criatividade, cooperação etc. são exemplos de valores autênticos, enquanto que valores como poder, riqueza material, status, dinheiro, competição, liderança, hierarquia etc. são valores constituídos socialmente e em contradição com a natureza humana, sendo, portanto, valores inautênticos (Viana, 2007, p.27).

Pode-se dizer, então, que há inversão de valores quando a aquisição de mercadorias se torna mais importante. 
Hoje a identidade (...) é a roupa, a mochila, o tênis, o tablet. (...) ele acessou o bem que está na moda, que pode ser o último carro, o tênis ou o tablet, aí é [que] o fetiche atingiu a todos independente de que condições (P1).

Isso é o que faz dar gancho para você discutir droga, se você não pertence aquele grupo social, você provavelmente irá censurar a conduta do menino que roubou o tablet ou o que compra o celular roubado (...). Tenho que me colocar no lugar desse grupo social para entender quais são os valores que esse grupo tem (P1).

Depois da nona oficina, o grupo promoveu a síntese final, e então decidiuse o nome do material gráfico, um caderno de título "Caderno de educação para ampliar a crítica sobre o consumo de drogas: como trabalhar com jovens".

O caderno foi então composto por três eixos - o primeiro deles é o que apresenta conteúdos que se propõem a analisar o fenômeno produçãodistribuição-consumo de drogas, com base na estrutura e dinâmica social contemporâneas. Esse eixo aborda a estrutura de classes sociais no modo de produção capitalista, a exploração entre elas e a produção das desigualdades sociais; o segundo eixo é composto por conteúdos da dimensão superestrutural da formação social - dimensão da qual faz parte o mecanismo da ideologia, que instrumentaliza a naturalização da divisão de classes, das desigualdades sociais, e os valores produzidos como parte desse mecanismo ideológico (competição, individualismo, consumo). O segundo eixo também contempla conteúdos a respeito do conceito de educação como instrumento de transformação ou de adaptação à ideologia dominante. O terceiro eixo apresenta conteúdos associados a respostas da juventude às contradições sociais. Uma delas, a organização política, se coloca como possibilidade de fortalecimento dos jovens e de enfrentamento aos desgastes vivenciados por eles.

As partes que compõem cada eixo são: um texto de apoio - elaborado para subsidiar a argumentação com os jovens; perguntas para incentivar a problematização do tema; indicação de filmes e outros textos para adensar as discussões; questões norteadoras - para incentivar a curiosidade e o aprofundamento da discussão; sugestões de estratégias pedagógicas - atividades educativas de possível realização com os jovens.

\section{Superações na compreensão do tema e novas sínteses}

O modelo hegemônico conhecido como 'guerra às drogas' propõe ações voltadas à prevenção de drogas e à abstinência, já que compreende o uso problemático de drogas como dependência. Está afiliado à concepção da multicausalidade do processo, na particularidade da compreensão de que 
doença ou agravo é o resultado do desequilíbrio de fatores relacionados ao ambiente, a características individuais do sujeito portador do agravo e do agente causador. No caso do uso problemático de drogas, o ambiente é o meio social; o sujeito é o usuário de drogas e o agente é a droga (Soares, 2007).

Esta é a perspectiva teórica que atribui a análise de situações que podem ser consideradas de risco ao sujeito ou à sociedade e, coerentemente, propõe intervençôes de diminuição e evitação de situações de riscos. No âmbito da prevenção, propõe ações elaboradas em níveis, determinados segundo a classificação de riscos (primária, secundária e terciária). Na esfera do tratamento do consumo prejudicial de drogas, as ações têm por objetivo a abstinência de drogas (Soares, 2007).

No entanto, centrar programas em fatores de risco, com vistas a minimizá-los, e operacionalizar ações em níveis de prevenção, não tem se mostrado eficiente para enfrentar o envolvimento dos jovens com o complexo fenômeno produção-distribuição-consumo de drogas.

Ao se propor crítico a essa perspectiva, o modelo da redução de danos apresentou-se de maneira multifacetada na sociedade, adotado segundo diferentes perspectivas que se desenvolveram num extremo como estratégias muito focais, e em outro como movimentos amplos por direitos sociais (Santos, Soares e Campos, 2010). Assim, foi incorporada pela saúde pública, muitas vezes de forma limitada, apenas na dimensão da redução de consequências advindas do consumo de drogas. Dessa forma, a despeito da existência das propostas amplas de RD, continuaram a predominar na saúde pública classificações de usuários de drogas de acordo com a relação estabelecida com a droga - consumidor ocasional, recreativo, dependente. As ações continuaram majoritariamente voltadas à prevenção, seguem a mesma classificação de riscos do modelo anterior - primária, secundária ou terciária - e utilizam estratégias para adaptação e mudanças de comportamentos relacionados ao uso de drogas (Soares e Campos, 2009).

Superar essa perspectiva significa partir da compreensão de que as raízes do envolvimento com as drogas assentam-se nas condições de reprodução social das classes sociais a que os jovens pertencem; ou seja, da determinação social do fenômeno (Soares e Campos, 2009).

Assim, toma-se como fundamental a compreensão da relação entre a inserção de classe na sociedade capitalista atual, a desproteção social e o consumo de drogas. Arruda et al. (2016) caracterizaram os perfis de reprodução social dos frequentadores de Cracolândia, região que concentra consumidores de crack na região central da cidade de São Paulo, e mostraram a relação entre a estrutura da sociedade no capitalismo atual, a desproteção social e a inserção de classe. Ao identificar que o problema da pobreza e da miséria na Cracolândia não é explicado pelo consumo de crack, mas pelo agravamento 
da questão social, o estudo mostrou que os sujeitos que estão inseridos nessa realidade são indivíduos que querem trabalhar, mas se sentem impotentes na ausência de oportunidades de trabalho formais ou decentes e, pela dificuldade de inserção social, acabam por recorrer ao consumo prejudicial de drogas.

Outros autores consideram também a importância da relação entre a inserção de classe na sociedade capitalista atual, a desproteção social e o consumo de drogas; destacam, no entanto, elementos mediadores como: socialização familiar (Souza, 2016), experiências intersubjetivas (Lima, 2016) e comportamentos relacionados à carência de recursos simbólicos, além das subjetividades dos envolvidos na relação social e dos mecanismos cognitivos e práticos de superação do consumo (Ramos, 2016).

Em vista dos resultados desses estudos, é imprescindível elaborar projetos de ação ancorados na perspectiva da educação emancipatória (Almeida, Trapé e Soares, 2013) que instrumentalizem os sujeitos envolvidos para apreenderem os determinantes sociais do processo saúde doença, o que permite que os sujeitos vislumbrem estratégias para a transformação da realidade.

A apreensão da realidade e do fenômeno trazido pelos envolvidos no processo educativo instrumentaliza a ação para transformar a realidade. Para isso, os participantes devem estar convictos de que a mudança é possível; é fundamental que o educador desafie os educandos a compreenderem criticamente a violência e a profunda injustiça que caracterizam sua situação concreta (Freire, 1996).

A metodologia da pesquisa-ação emancipatória coaduna-se com essa perspectiva, uma vez que possibilita que os envolvidos problematizem criticamente a realidade em que vivem e que delineiem uma proposta de resposta, de enfrentamento da questão que mobilizou todo o processo.

É possível verificar esse percurso em resultado de pesquisa-ação emancipatória (PAE) desenvolvida em 13 oficinas com jovens estudantes de escola pública no município de São Paulo. Os resultados mostraram o processo de reflexão e a síntese produzida - a associação entre capitalismo e consumo de drogas e a elaboração coletiva de roteiros para programas de rádio para abordar o tema do consumo de drogas (Oliveira, Soares e Silva, 2016).

$\mathrm{O}$ mesmo pode ser evidenciado em resultado de PAE com agentes comunitários de saúde da região sudeste do município de São Paulo, desenvolvida em 15 oficinas. A síntese final foi a produção do caderno "Álcool e outras drogas: um milhão de ações. Caderno de Trabalho do Agente Comunitário de Saúde: em foco as necessidades de saúde e o consumo prejudicial de drogas" (Cordeiro e Soares, 2015).

Assim, a intervenção educativa no âmbito do consumo de drogas deve subsidiar os jovens na compreensão de que a classe trabalhadora está submetida ao sistema capitalista de exploração, o que não lhe permite se apropriar 
dos bens que produzem. Compreender as diferenças de classe e de acesso aos bens possibilita a denúncia das raízes dos problemas advindos do consumo de drogas e o desenvolvimento de práticas que considerem o consumidor de drogas como sujeito de direitos e que consigam realizar mudanças sociais com o objetivo da igualdade (Soares e Campos, 2009).

\section{Conclusão}

A PAE efetivou a elaboração do caderno "Educação sobre drogas: como trabalhar com jovens", uma proposta de superação dos materiais que apoiam os processos educativos em saúde, majoritariamente de caráter disciplinador e aterrorizante, que despolitizam os jovens quanto à realidade do consumo de drogas.

O material educativo elaborado partiu de conhecimentos científicos e críticos sobre o consumo de drogas na atualidade, com potencial para desmistificar o consumo e expor suas contradições. O caderno construído segue os princípios da educação emancipatória, o que o coloca em situação favorável à aproximação com os jovens em diferentes áreas de atuação, bem como ao encaminhamento de discussão crítica sobre o tema.

\section{Colaboradores}

Iara Ribeiro Paixão e Cassia Baldini Soares foram responsáveis pela concepção da pesquisa, análise e interpretação dos dados, e redação do artigo. Luiza Carraschi de Oliveira participou da análise dos resultados e redação do artigo. Luciana Cordeiro, Carla Andrea Trapé e Célia Maria Sivalli Campos participaram da redação e revisão crítica do artigo. 
Resumen El objetivo de este artículo es presentar el proceso de elaboración de material educativo para apoyar acciones con jóvenes en la temática de las drogas, resultado de la investigación acción emancipadora, desarrollada durante 14 talleres, con investigadores y trabajadores de la salud. Se organizó en tres ejes: la dimensión estructural, que analiza el fenómeno producción-distribuciónconsumo de drogas en el contexto de la estructura y dinámica social contemporánea; la dimensión superestructural, que discute la ideología y los valores hegemónicos en la sociedad contemporánea y su relación con el fenómeno de las drogas; y el eje que analiza las respuestas de los jóvenes a las contradicciones sociales, con una discusión sobre la posibilidad de una organización política como un proceso de fortalecimiento de la juventud para enfrentar la angustia. Las partes que componen cada eje son: un texto base; indicación de películas y textos complementarios; preguntas para profundizar la discusión; estrategias pedagógicas. El material didáctico favorece procesos educativos críticos y radicales, aquellos que exponen las contradicciones sociales que están en la base del fenómeno producción-circulación-consumo de drogas, y superan formaciones que se centran en el medicamento y que culpan al usuario, procesos que comúnmente alejan jóvénes de la discusión.

Palabras clave usuario de drogas; educación para la salud; jóvenes; enfermería; investigación-acción

\section{Notas}

${ }^{1}$ Prefeitura Municipal de São Paulo, São Paulo, SP, Brasil.

<iarapaixao@hotmail.com>

Correspondência: Prefeitura Municipal de São Paulo, Suvis Itaim Paulista, Rua Ererê, 260, Vila Curuçá, CEP 08030-400, São Paulo, SP, Brasil.

${ }^{2}$ Universidade de São Paulo, Departamento de Enfermagem em Saúde Coletiva, São Paulo, São Paulo, Brasil.

<cassiaso@usp.br>

${ }^{3}$ Universidade de São Paulo, Departamento de Enfermagem em Saúde Coletiva, São Paulo, São Paulo, Brasil.

$<$ luiza.carraschi.oliveira@usp.br>

${ }^{4}$ Universidade de São Paulo, Departamento de Enfermagem em Saúde Coletiva, São Paulo, São Paulo, Brasil.

<lucordeiro.to@gmail.com>

${ }^{5}$ Faculdade das Américas, Curso de Enfermagem, São Paulo, São Paulo, Brasil. <carlatrape@yahoo.com.br>

${ }^{6}$ Universidade de São Paulo, Departamento de Enfermagem em Saúde Coletiva, São Paulo, São Paulo, Brasil.

$<$ celiasiv@usp.br> 


\begin{abstract}
${ }^{7}$ Um conjunto de indivíduos que compartilham o mesmo modo de vida, interesses e oposição a outras classes sociais, aspectos derivados da atividade fixada pela divisão social do trabalho, que, por sua vez, é determinada pelas relações de produção dominantes. No caso do capitalismo, as diversas classes sociais existentes estão intimamente ligadas ao processo de divisão social do trabalho gerado pelas relações de produção capitalistas (Viana, 2012, p.145).

${ }^{8}$ Dermeval Saviani formulou a pedagogia histórico-crítica, introduzida no país a partir de 1979. Ela pressupõe o empenho em compreender a questão educacional com base no desenvolvimento histórico objetivo, na concepção do materialismo histórico, com base na determinação das condições materiais da existência humana e na concepção dialética da história, cujo compromisso seja a transformação da sociedade (Saviani, 2003).

${ }^{9} \mathrm{O}$ artigo é produto de dissertação de mestrado, intitulada Pesquisa-ação emancipatória para construção de material de apoio a atividades educativas sobre drogas, de autoria de Iara Ribeiro Paixão, apresentada em 2016, no Programa de Pós-Graduação, Mestrado Profissional em Enfermagem na Atenção Primária em Saúde no SUS. O material educativo construído nesta pesquisa-ação pode ser encontrado on-line no site: $<$ http:// fortalecimentoedesgaste.com.br>.
\end{abstract}

\title{
Referências
}

ARGUELLO, Katie S. C.; DIETER, Vitor S. Política criminal das drogas: o proibicionismo e seu bem jurídico. In: MEZZAROBA, Orides et. al. (orgs). Direito penal e criminologia. Curitiba: Clássica Editora, 2014. (Coleção Conpedi/ Unicuritiba, v. 17). Disponível em: <https:// slides.tips/politica-criminal-das-drogas-oproibicionismo-e-seu-bem-juridico.html $>$. Acesso em: 1 de fev. 2018.

ALLARA, Elias et al. Are mass-media campaigns effective in preventing drug use? A Cochrane systematic review and meta-analysis. $B M J$ Open, v. 5, n. 9 p. 1-5, 2015. Disponível em: <http://bmjopen.bmj.com/content/5/9/e007449. full $>$. Acesso em: 10 nov. 2016.

ALMEIDA, Alva H.; TRAPÉ, Carla A.; SOARES, Cassia B. Educação em saúde no trabalho de enfermagem. In: SOARES, Cassia B.; CAMPOS, Célia M.S. (org.). Fundamentos de saúde coletiva e o cuidado de enfermagem. São Paulo: Manole, 2013. p. 293-322.

ALVES, Vânia S. Modelos de atenção à saúde de usuários de álcool e outras drogas: discursos políticos, saberes e práticas. Cadernos de Saúde Pública, Rio de Janeiro, v. 25, n. 11, p. 2.3092.319, 2009.

ARRUDA, Marcel S. B. et al. Crackland: Beyond Crack Cocaine. Social Medicine, New York, v. 11, n. 1 p. 8-17, 2017.

BIRMAN, Joel. Arquivos do mal-estar e da resistência. Rio de Janeiro: Civilização Brasileira, 2006.

BIRMAN, Joel. Tatuando o desamparo: a juventude na atualidade. Cadernos sobre o mal: agressividade, violência e crueldade. Rio de Janeiro: Record, 2009. p. 191-208. 
BOITEUX, Luciana. El antimodelo brasileño: prohibicionismo, encarcelamiento y selectividad penal frente al tráfico de droga. Nueva Sociedad, Buenos Aires, n. 255, p. 132-44, 2015.

BRASIL. Presidência da República, Secretaria Geral. Mapa do encarceramento: os jovens do Brasil. Brasília, 2015. Disponível em: <http://juventude.gov.br/articles/participatorio/0010/1092/Mapa_do_Encarceramento_-_Os_jovens_do_brasil.pdf > . Acesso em: 12 nov. 2016.

CARNEIRO, Henrique. Transformações do significado da palavra 'droga': das especiarias coloniais ao proibicionismo contemporâneo. In: VENÂNCIO, Renato P.; CARNEIRO, Henrique; GONÇALVES, Andréa L. (orgs.). Álcool e drogas na história do Brasil. São Paulo: Alameda, 2005. p. 11-27.

CARDOSO, Bianca S. et al. Materiais educativos sobre drogas: Uma análise qualitativa. Saúde e Transformação Social, Florianópolis, v. 4, n. 2, p. 149-156, 2013.

CORDEIRO, Luciana; GODOY, Aline; SOARES, Cassia B. A supervisão como processo educativo: Construindo o paradigma de redução de danos emancipatória com uma equipe de CAPS-AD. Cadernos de Terapia Ocupacional da UFSCar, São Carlos, v. 22, supl. esp., p. 153-159, 2014.

CORDEIRO, Luciana; SOARES, Cassia B. Processo de trabalho na atenção primária em saúde: pesquisa-ação com agentes comunitários de saúde. Ciência \& Saúde Coletiva, Rio de Janeiro, v. 20, n. 11, p. 3.581-3.588, 2015.

DOWBOR, Ladislau. A economia da família. In: ACOSTA, Ana R.; VITALE, Amalia F. (orgs.). Família: redes, laços e políticas públicas. 5 . ed. São Paulo: Cortez, 2010. p. 293-316.

FAGGIANO, Fabrizio et al. School-based prevention for illicit drug use. Cochrane Database of Systematic Reviews, n. 12, art. n. CD003020. 2014. Disponível em: <http:// www.cochrane.org/CD003020/ADDICTN_schoolbased-prevention-illicit-drug-use $>$. Acesso em: 12 nov. 2016.

FLETCHER, Adan; BONELL, Chris; HARGREAVES, James. School effects on young people's drug use: a systematic review of intervention and observational studies. Journal of Adolescence Health, v. 42, n. 3, p. 209-220, 2008.

FREIRE, Paulo. Pedagogia da autonomia. Saberes necessários à pratica educativa. Rio de Janeiro: Paz e Terra, 1996.

FREITAS, Fernanda V.; REZENDE FILHO, Luiz A. Modelos de comunicação e uso de impresso na educação em saúde: uma pesquisa bibliográfica. Interface: Comunicação, Saúde e Educação, Botucatu, v. 15, n. 36, p. 243-255, 2011.

GATES, Simon et al. Interventions delivered to Young people in non-school settings for the prevention of drug use. Cochrane Database of Systematic Reviews, n. 1, art. n. CD005030. 2006. Disponível em: <http://www.cochrane. org/CD005030/ADDICTN_interventionsdelivered-toyoung-people-in-non-schoolsettings-for-the-prevention-of-drug-use $>$. Acesso em: 11 nov. 2016.

GLOBAL COMMISSION ON DRUG POLICY. Report of the Global Commission on Drug Policy. 2011. Disponível em: <http://www. globalcommissionondrug.org/reports $>$. Acesso em: 17 nov. 2016.

LIMA, Andressa L. M. A miséria moral da ralé. In: SOUZA, Jessé (org.). Crack e exclusão social, Brasília: Ministério da Justiça e Cidadania, 2016. p. 39-74.

NOGUEIRA, Maria J. et al. Criação compartilhada de um jogo: um instrumento para o diálogo sobre sexualidade desenvolvido com adolescentes. Ciência \& Educação, Bauru, v. 17, n. 4, p. 941-956, 2011. 
OLIVEIRA, Elda; SOARES, Cassia B.; SILVA, Julia A. Pesquisa-ação emancipatória com jovens escolares: relato de experiência. Revista Gaúcha de Enfermagem, Porto Alegre, v. 37, n. 3, p. 1-6, 2016.

OLIVEIRA, Lucia M. P. Desenvolvimento de processo e produto socioeducativo promovendo saúde em uma sala de espera. 2011. Dissertação (Mestrado em Ensino em Biociências e Saúde) - Fundação Oswaldo Cruz, Instituto Oswaldo Cruz, Rio de Janeiro, 2011.

PEREIRA-PEREIRA, Potyara A. Mudanças estruturais, política social e papel da família: crítica ao pluralismo de bem-estar. In: SALES, Mione A.; MATOS, Maurílio C.; LEAL, Maria C. (orgs.). Política social, família e juventude: uma questão de direitos. Cortez, São Paulo, 2010. p. 25-42.

RAMOS, Lucas H. Abandonados anônimos. In: SOUZA, Jessé (org.). Crack e exclusão social, Brasília: Ministério da Justiça e Cidadania, 2016, p. 75-102.

RIBEIRO, Fernanda M. L.; MINAYO Maria C. S. As comunidades terapêuticas religiosas na recuperação de dependentes de drogas: o caso de Manguinhos, RJ, Brasil. Interface: Comunicação, Saúde e Educação, Botucatu, v. 19, n. 54, p. 515-526, 2015.

SAFATLE, Vladimir. O circuito dos afetos: corpos políticos, desamparo e o fim do indivíduo. 2. ed. Belo Horizonte: Autêntica, 2016.

SANTOS, Vilmar E. O objeto/sujeito da redução de danos: uma análise da literatura da perspectiva da Saúde Coletiva. 2008. $210 f$. Dissertação (Mestrado em Enfermagem) - Escola de Enfermagem, Universidade de São Paulo, São Paulo, 2008.

SANTOS, Vilmar E.; SOARES, Cassia B.; CAMPOS, Célia M. Redução de danos: análise das concepções que orientam as práticas no Bra- sil. Saúde Coletiva, São Paulo, v. 20, n. 3, p. 995-1.015, 2010.

SAVIANI, Dermeval. Pedagogia histórico-crítica: primeiras aproximações. 8. ed. Campinas: Autores Associados, 2003.

SILVA, Madalena A. Construção de uma estratégia didática para a utilização das cartilhas 'Os caminhos da esquistossomose' em escolas públicas de Ensino Fundamental, no município de Barra Mansa/RJ. 2012. 96f. Tese (Doutorado em Biociência e Saúde) - Fundação Oswaldo Cruz, Instituto Oswaldo Cruz, Rio de Janeiro, 2012.

SOARES, Cassia B. Consumo contemporâneo de drogas e juventude: a construção do objeto na perspectiva da Saúde Coletiva. 2007. 207f. Tese (Livre-docência em Enfermagem) - Escola de Enfermagem, Universidade de São Paulo, São Paulo, 2007.

SOARES, Cassia B. Mais que uma etapa do ciclo vital: a adolescência como um construto social. In: BORGES, Ana L.V.; FUJIMORI, Elizabeth (org.). Enfermagem e a saúde do adolescente na atenção básica. Barueri: Manole, 2009a. p. 3-22.

SOARES, Cassia B. Agências de socialização e valores sociais. In: BORGES, Ana L. V.; FUJIMORI, Elizabeth (orgs.). Enfermagem e a saúde do adolescente na atenção básica. Barueri: Manole, 2009b. p. 61-81.

SOARES, Cassia B.; CAMPOS, Célia M. S. Consumo de drogas. In: BORGES, Ana L.V.; FUJIMORI, Elizabeth (orgs.). Enfermagem e a saúde do adolescente na atenção básica. Barueri: Manole, 2009. p. 436-468.

SOARES, Cassia B.; CORDEIRO, Luciana; CAMPOS, Célia M.S. Pesquisa-ação emancipatória: uma proposta metodológica essencial para a enfermagem. In: SEMINÁRIO NACIONAL DE PESQUISA EM ENFERMAGEM, 2013, Natal, 
Rio Grande do Norte. Associação Brasileira de Enfermagem. Disponível em: <http://www. abeneventos.com.br/anais_senpe/17senpe/ pdf/9026me.pdf>. Acesso em: 17 nov. 2016.

SOARES, Cassia B. et al. Juventude e consumo de drogas: oficinas de instrumentalização de trabalhadores de instituições sociais, na perspectiva da saúde coletiva. Interface: Comunicação, Saúde e Educação, Botucatu, v. 13, n. 28, p. 189-199, 2009.

SOARES, Cassia B.; JACOBI, Pedro R. Adolescentes, drogas e Aids: avaliação de um programa de prevenção escolar. Cadernos de Pesquisa, São Paulo, n. 109, p. 213-237, 2000.

SOUZA, Jessé. A doença da humilhação. In: SOUZA, Jessé (org.). Crack e exclusão social, Brasília: Ministério da Justiça e Cidadania, 2016. p. 29-37.

VIANA, Nildo. Classes sociais, condições de vida e processo saúde-doença. Estácio de Sá, Goiânia, v. 2, n. 7, p. 139-151, 2012.
VIANA, Nildo. Os valores na sociedade moderna. Brasília: Thesaurus, 2007.

WAISELFIZ, Julio J. Mapas da violência 2015. Mortes matadas por armas de fogo. Brasília, 2015. Disponível em: <http://www.mapadaviolencia.org.br/pdf2015/mapaViolencia2015. pdf>. Acesso em: 15 nov. 2016.

ZACCONE, Orlando. Combate às drogas e o respeito aos direitos humanos. In: CONFERÊNCIA INTERNACIONAL DE DIREITOS HUMANOS, 5. 2012. Disponível em: <https://youtu.be/ KTWc3Eo_CpI>. Acesso em: 16 fev. 2018.

Recebido em 25/11/2016. Aprovado em 23/01/2017. 